\title{
Southern Think Tank Partnerships in the Era of the 2030 Agenda
}

\author{
Andrea Ordóñez-Llanos
}

\subsection{INTRODUCTION}

More than ever, there is a growing realisation of the importance of global issues-specifically those that go beyond national borders, either because they are not divisible or because they are persistent across diverse countries and regions. With a global policy agenda in the form of the 2030 Agenda for Sustainable Development, the central questions relate to how these decisions will be made and the type of knowledge that will inform such an agenda. This chapter focusses on the emergence of Southern think tanks as actors in the debates on global development and examines their engagement with global policy debates.

Southern think tanks are important actors that generate evidence for policy debates and create spaces for dialogues on difficult policy choices by becoming brokers of diverse perspectives. Through these strategies, Southern think tanks have in many instances successfully influenced policy processes and outcomes (Ordóñez et al. 2012). These institutions, by their very definition, work within the intersection of policy and knowledge and bridge connections between diverse actors through policy debates. With the 2030 Agenda and the new impetus towards working through partnerships, think tanks have the potential of becoming key actors that enable these collaborations. This chapter explores the relationships between think tanks from the Global South with each other,

\footnotetext{
A. Ordóñez-Llanos $(\bowtie)$

Southern Voice, Lima, Peru

e-mail: andrea@southernvoice.org

URL: http://www.southernvoice.org

(C) The Author(s) 2021 
their Northern peers, and the broader international community. The final objective is to explore how think tanks are positioned to engage in partnerships and to determine the critical factors that can enable their participation in such collaborations.

The Sustainable Development Goals (SDGs) are part of the consolidation of global policy-making processes ever since the creation of the United Nations and other multilateral organisations. Stone uses the metaphor of "agora" to describe global policy-making because it refers to the "growing global public spaces of fluid, dynamic and intermeshed relations of politics, markets, culture and society. This public space is brought about by the interactions of its actors" (Stone 2013, p. 17). Thinks tanks have become important actors in these processes. This relational view of global policy-making processes highlights the disconnect between the national policy-making processes and the global ones. The global processes cannot be considered an aggregation of the national-level policy ones, but rather distinct processes in themselves. Stone also notes the differences in the actors involved compared to those in the national policymaking processes, including what she calls "internationalised public sector officials", "international civil servants", and "transnational policy professionals", all of whom interact to shape global policy. The exchanges among these actors are fluid and do not follow national divisions. For example, a delegation to the United Nations in country A may reach out to experts from country $\mathrm{B}$ for advice or respond to pressures from an international non-governmental organisation in a different country. This is not to say that there are no lines of accountability - especially from the "internationalised public sector officials"to their respective governments and citizens, but that these other drivers are also at play at the global level. In this context, think tanks themselves are evolving as organisations with the capacity to navigate both national and global contexts and to talk to a diversity of global actors, not only those within their national policy context.

Think tanks are a growing group of actors engaged in policy debates worldwide. As of 2018, the Open Think Tank Directory accounts for 2714 think tanks worldwide. ${ }^{1}$ In Africa, there are 106; in Latin America and the Caribbean 624; and 520 in Asia-in total representing 46.06 per cent of the total entries in the database. ${ }^{2}$ Although the think tank tradition was born in "Western" democracies such as the United States and the UK, their presence in the Global South is significant. Among them, there are varying types of organisations, ranging from well-established with a long tradition of working on policy issues, to newer and more nimble ones. From the total universe of think tanks, a smaller number of organisations work on development issues or engage with the global debates on development. However, because of the diverse and fluid nature of these organisations, it is hard to classify them purely along their thematic or geographic reach. ${ }^{3}$ Nonetheless, some of these think tanks - and among these some specific researchers and policy experts—act as what Stone defines as "transnational policy professionals", meaning experts that provide policy advice to diverse countries, multilateral organisations, and other global institutions. 
Think tanks located in the Global North that work on development issues traditionally had more access to global policy processes, such as debates held at the United Nations, the World Trade Organization, and multilateral organisations. They have developed presence and reputation in these debates, thanks in part to being located in or close to the cities where global debates take place, such as New York or Geneva, and having access to financing opportunities from countries in the Global North. Stone (2001) identifies some key factors that enable think tanks to engage in global debates: (i) a vibrant and critical national scene for think tanks, (ii) funding opportunities, (iii) freedom of speech, and (iv) "pull" factors, such as the demand from institutions such as the European Union or the United Nations. Staff members of these think tanks can easily move between their organisations within the multilateral or diplomatic sphere in what is usually referred to as the revolving door (Stone 2007). Although think tanks from the Global South have traditionally had less prominence in global development debates, new technologies-as well as the new framing of the 2030 Agenda, an inclusive global development plan of action-create opportunities for more proactive participation. The next section explores how the framing of the 2030 Agenda may shape the knowledge produced by think tanks and other policy experts. The following three sections explore in detail how Southern think tanks relate to each other and other actors involved in global policy-making, such as their Northern peers, civil society, governments, and the private sector. A final reflection focusses on how think tanks from the Global South can collaborate more with others.

\subsection{THE IMPLICATIONS OF THE 2030 Agenda for Think Tanks}

Although criticisms about the viability and technical soundness of the 2030 Agenda and the SDGs abound, the agenda remains a powerful tool to re-frame how different knowledge actors engage in the "global agora" of development debates. ${ }^{4}$ The first aspect of the SDGs that shapes the research agendas is their universality. This shift also affects the primary locus of research on development. Before the 2030 Agenda, development was perceived as an agenda for developing countries only; research on development focussed mainly on countries in the Global South. This focus somewhat expanded beyond the Global South through research on international cooperation and also through research on policy coherence for development. The effectiveness of development cooperation research, for example, explores the challenges of cooperation between donor and recipient countries, which may include issues of the recipient as well as of the provider of cooperation (Howes 2014). The research on policy coherence went beyond development assistance; it explored how a diversity of other policies by donor countries (trade, intellectual property, or migration) affect-directly or indirectly-the success of development programmes and policies in developed countries (Ashoff 2005). However, the shift in focus of development from being an agenda only for the 
Global South to one that includes all countries is different since, in a universal agenda, domestic policies in developed countries also become relevant areas of research. This is particularly true in the context of the degree of progress on different social, environmental, and economic indicators, which show a growing convergence across countries, but more extensive divergence within countries (Horner and Hulme 2019). Although the differences between countries remain, the normative divisions between "developed" and "developing" lose ground, as goals and targets are expected to be reached by all countries, independent of their level of economic development.

Furthermore, the differences among countries from the Global South are growing, and referring to them as one group of developing countries is becoming less useful in practical terms. Geopolitically, however, it has been useful for nations to have a joint group (such as the G77) for development debates to strengthen their presence globally (Perkins 2013). In short, the 2030 Agenda changes the paradigm - from a focus on the Global South to an understanding of development as a global agenda across countries of all income levels. As a result, the knowledge required to inform the implementation of such an agenda is also broader.

For development research and policy analysis, this may be summarised in what Horner and Hulme (2019) have labelled a shift from international to global development. For think tanks, a universal agenda may entail the expansion of their reach beyond national settings. Indeed, "Western" think tanks have been experiencing these changes through the expansion and internationalisation of their work while seeking out new horizons beyond their national borders and establishing offices in important capitals of the world as they pursue new audiences, funding, and networks (Niblett 2018). Think tanks of the Global South have less experience internationalising their presence. Some of the possible reasons for this is that these think tanks are newer institutions with research agendas that are predominately focussed on national issues. Furthermore, the disconnect among countries in the Global South has allowed for fewer interactions among researchers across regions.

Nonetheless, the SDGs create the opportunity to engage further in global debates by bringing particular perspectives to dialogues on what an international agenda means for diverse national and subnational realities (Bhattacharya and Ordóñez-Llanos 2016). Part of the challenge of a global agenda is to make it relevant in different contexts. For this challenge, think tanks from the South can provide nuanced research that is grounded in the reality of different contexts and can bridge national and global debates.

The second aspect of the SDGs that impacts the research agendas is that they incorporate environmental, social, and economic dimensions of wellbeing. The broadening of the development agenda means that knowledge that focusses on coming to a better understanding of the interconnected nature of societal change will become more valuable. At the same time, it means that policy processes and spaces will transform from being sector-specific to becoming inter-sectoral. A think tank that worked in a particular policy area 
may find itself working with actors well beyond its original scope to include others that were not previously involved in a given issue. What does this mean for think tanks in the Global South?

By putting partnerships and non-state actors at the centre of its approach (SDG 17), the 2030 Agenda emphasises a change that the world has already begun to experience: multi-level, multi-actor governance. This third aspect encompasses a change from centralised, government-led policy processes to an interconnected network of various actors making decisions and implementing them. The shift began already before the adoption of the 2030 Agenda; however, it is now an official global policy document. These changes in the processes of global policy-making also affect the traditional work of think tanks around the world. The traditional approach of think tanks was to talk directly to policy-makers and provide specific ideas and advice. However, this model does not fit anymore, given that there are many more actors involved in the policy-making processes. Formal and informal consultations with civil society, the influence of lobby groups, and decentralised policy-making are some of the factors that have led more actors to become involved. In this context, it is essential to ask: To whom do the think tanks speak to? How do they conduct their research? And for whom is their policy analysis relevant? This chapter focusses mainly on how think tanks engage in these processes through the formation of different types of partnerships and collaborations.

In summary, the 2030 Agenda, as a normative proposition, shifts the work of think tanks: towards a global understanding of development issues, towards a more interdisciplinary research agenda, and towards new strategies to reach and inform policy. Despite the stated partnership approach, it is essential to note that inherited power asymmetries in the global debates persist. These asymmetries shape the extent to which these partnerships can be horizontal. They also represent the variety of interests these partnerships bring together and whether they reproduce power asymmetries, thus promoting primarily the interests of those who have more power to begin with.

A parallel phenomenon is occurring thematically. The 2030 Agenda explicitly states that all the dimensions of sustainable development-economic, social, environmental, institutional-are equally relevant. Nonetheless, this does not necessarily translate into a balanced approach at the time of planning and implementing policy. Having a holistic approach that takes into consideration all of these dimensions requires better coordination in policy-makingexplicitly interdisciplinary research. For think tanks and policy experts, this also means that their approaches to research should also evolve.

The 2030 Agenda sets the goals for more collaboration and partnerships. As explored before, however, inherited power asymmetries cannot be overlooked. The following section analyses the respective relationships that are emerging among think tanks from the Global South and beyond. 


\subsection{Collaboration and Contestation with And Among Think Tanks: "The Four-C's Model"}

The 2030 Agenda has proposed significant normative changes to what development is and how it should be achieved, including a strong emphasis on partnerships. In practice, a variety of relationships will emerge, and the different actors will need to adapt to them. In this context, it is relevant to understand the relationships that emerge, how the actors share power, and what enables vital partnerships.

Najam (2000) explains the nature of relations between non-governmental organisations (NGOs) and governmental organisations and proposes a conceptual framework denominated the Four-C's model. This model is based on a theory of strategic institutional interests, and it proposes that relations boil down to a question of ends and means. This framework can also be useful for exploring relations among a variety of actors. In this case, it will be used to explore the nature of the relationships between think tanks and the diversity of actors involved in the global policy debates of the SDGs.

There are four types of relationships that are based on the strategies and goals each actor has in a given policy process (Najam 2000): (i) cooperation, (ii) confrontation, (iii) complementarity, or (iv) co-optation. Cooperation occurs when NGOs and government agencies share similar strategies for achieving similar policy goals. Hence, there is a convergence of preferred ends as well as means. Confrontation happens when NGOs and governmental agencies perceive the other's strategies and goals to be antithetical to their own. Some scholars consider this to be the natural order of things because NGOs and governments often find themselves-explicitly or implicitly-in adversarial relationships. Najam's model defines confrontation as encompassing not just acts of coercive control by the government but also policy defiance and opposition by NGOs. Complementarity occurs when two actors prefer different strategies but share similar goals. Najam describes this type of relationship as a function of goals. When both parties share similar goals, it is more likely that they can reach an agreement in which they complement each other in the achievement of a shared outcome. Finally, Najam mentions co-optation as another type of relationship. This is when both parties prefer different goals but share similar strategies; such situations are often transitory. Najam (2000, p. 389) points out that

as each side tries to change the goal preference of the other side, the discomfort is likely to be directly proportional to the power asymmetry. It is the power asymmetry that will decide whether, and which, side gives in or gives up - the instability is resolved as the relationship moves to one of the other three boxes. 
As discussed in the previous section, there are a diversity of actors and policy areas in play-a perfect scenario for complex relationships. The following sections explore how think tanks from the Global South interact among themselves and with other key actors and analyse the extent to which they can engage in partnerships and other cooperation strategies.

\subsection{Collaboration Among Think Tanks in the Global South}

Analysing the relationships between think tanks from the Global South through the Four-C's model reveals that the think tanks remain collaborative in the context of the global development agenda. They have identified both the common goals and the strategies that foster collaboration. Networks of think tanks emerging from the Global South serve various purposes: they support the shaping of a common agenda among countries, sustaining spaces for informal diplomacy as an alternative to delicate official diplomacy when obstacles emerge, and they can position Southern think tanks vis-à-vis their Northern peers.

The Association of Southeast Asian Nations (ASEAN) Institutes of Strategic and International Studies network is one such example. Although it was formally launched as an association in 1988, it emerged from earlier conversations and dialogues among think tanks from core ASEAN countries. Through informal diplomacy, joint research efforts, and constant dialogue, the network has been able to establish regional positions and develop a collaborative research agenda. The network filled an existing gap in providing knowledge and policy advice to the ASEAN Secretariat, and it has had an essential role in setting an agenda for ASEAN collaboration (Stone 2013). The ASEAN Secretariat now officially seeks out input and collaborations with think tanks from the region (Association of Southeast Asian Nations 2019). Furthermore, with the creation of the ASEAN+3 forum, which includes China, Japan, and South Korea, the Network of East Asian Think-Tanks was established as a recommendation from the East Asia Vision Group in 2003 with organisations designated by the respective governments. It is conceived as a space for "Track 2" diplomacy to support the forum (Council on East Asian Community, n.d.). The experiences of ASEAN countries exemplify not only the interest of think tanks to collaborate but also the interest of governments to promote this collaboration and engage with think tanks. However, all of these networks emerged and were conceived before the 2030 Agenda. With ASEAN becoming an effective platform for the SDGs in the region, different networks may emerge as ASEAN engages with other development actors and think tanks that go beyond international relations towards more development policy. In order to lead on sustainable development, ASEAN will need to strengthen its policy-research capacity at the regional and national levels (Parks et al. 2018). This model of cooperation shows an evolution from a focus on diplomatic brokerage to more in-depth policy discussions. 
The BRICS (Brazil, Russia, India, China, and South Africa) Think Tanks Council was created in 2013 as an extension of the summit of the emerging powers with objectives of "forming a platform for the exchange of ideas among researchers, academia and think tanks; convening the annual BRICS Academic Forum; and making policy recommendations and giving guidance to the BRICS Leaders for consideration" (Department of International Relations and Cooperation Republic of South Africa 2013). Similar to the Network of East Asian Think-Tanks, the BRICS Think Tanks Council emerged from an official mandate, which may put pressure on the independence of the networks and their flexibility to adapt and evolve. In this model of cooperation, as with the ASEAN model, it is essential to note the relevance of the support from governments and the clear mandate for collaborating.

Another collaboration among think tanks from the Global South is the Network of Southern Think Tanks (NeST) ${ }^{5}$ which works to generate and consolidate knowledge on South-South cooperation (SSC). It was launched during the Mexico High-Level Meeting on Effective Development Cooperation in 2014, at a time when the debates on development cooperation were at a difficult stage. At this point of the global process, the Global Partnership for Effective Development Co-operation was created with the expectation of bringing new actors into the debates on development cooperation-mainly countries with emerging economies, since they were not engaged in the previous debates on effective development cooperation. Given the lack of formal agreement between governments, it was important, in this context, for government and non-government think tanks to initiate a network to shape SSC at a technical level (Shankland and Constantine 2014). NeST was convened by think tanks from India, South Africa, Brazil, and China. Two Northern-based think tanks were also invited as observers, signalling an interest of further engaging with Northern peers in the debates on cooperation. Using technical information, the research from the network backs the political discussions on SSC, mainly through the lenses of SSC providers. The network also fills an existing gap, as SSC processes have received much less attention than those for North-South cooperation in terms of global normsetting. The NeST model showcases an example of a hybrid space between government and non-government think tanks that enables the co-production of research while maintaining a close connection with inter-governmental processes.

Southern Voice, a network of 51 think tanks from Africa, Asia, and Latin America, was founded in 2012. The founding members of the network were all part of the Think Tank Initiative, a multi-donor programme managed by the Canadian government's International Development Research Centre that aimed to strengthen think tanks' capacities in various countries. Meetings across regions for the first time created a unique opportunity to identify alternatives to collaborate and influence global debates. The main goal of the network remains repositioning research and policy analysis from developing countries and serving as an open platform for the debates on the SDGs. 
Southern Voice "informs global discussions by bringing national and regional knowledge, along with a sense of realism and pragmatism, to the table" (Bhattacharya and Ordóñez-Llanos 2016, p. 4). Since its inception, Southern Voice has generated evidence around a variety of topics related to the SDGs, from its design and implementation to the data required for its proper evaluation. Southern Voice's contribution is to create an independent space for thinking strategically about long-term policy changes as well as issues that may not be a priority in current debates. Although independence is important, this model has the challenge of continually finding the links to the policy arena.

These models of networks and collaborations among think tanks from the Global South show that they can identify similar strategies and goals, which lead to collaborations, as described in the Four-C's model. The objectives may be to strengthen a regional or thematic position, to facilitate a technical dialogue among diverse groups, or to create new policy ideas and narratives. These networks all respond to an asymmetry of knowledge and power between the North and the South in global debates and the realisations that, for Southern governments, having a stronger position on global policy dialogues requires up-to-date knowledge and evidence as well as innovative ideas and propositions. Think tanks can play a role, either by building bridges among themselves or with governments and regional bodies.

\subsection{North-South Think Tank Collaborations}

As the 2030 Agenda requires broader consensus-building across countries of different regions and at different levels of economic development, new partnerships may emerge for this purpose. Think tanks and academic institutions can promote action by "addressing the North-South divide that often plagues these discussions by enabling more South-South partnerships and by coming together beyond such divides to take the Agenda forward" (Jha et al. 2016, p. 2). Can such partnerships emerge that go beyond the North-South divide?

Collaborations among think tanks from the North and South for working on development are not new and may be seen as mechanisms to increase the reach of think tanks from the Global North and improve the capacities of peers in the Global South (Kimenyi 2013). But these collaborations have focussed more on research and capacity-building than informing global policy-making. The fact that the previous development agenda did not have a global reach may help explain the limited opportunities for more formal global think tank networks to emerge.

The process of the Think 20 (T20) network may be evolving in nature to include a broad range of think tanks from diverse regions to inform this global policy-making space. T20 originated in 2012 and is part of the engagement mechanisms of the G20. There are several engagement groups for businesses, civil society, and labour unions, among others, and together they comprise the consultative processes of the G20 process. No clear set of rules define the participation or decision-making processes-these change every year due to 
the rotating G20 presidency. Each government defines the co-chairs of the different engagement groups. As a result, the legitimacy of the composition and the importance of each group changes with the host country (Alexander and Löschmann 2016). In 2017, during the German presidency, the presence of the engagement groups and the levels of diversity increased. Under the presidency of Argentina in 2018, the T20 network expanded further, with the Argentinean co-chairs explicitly aiming to increase the reach of the network to include think tanks beyond the G20 countries. They acknowledged that G20 policies have an impact beyond the national borders of G20 countries. The regional representation of Africa in these engagement groups is particularly limited, as South Africa is the only formal African member of the G20. Within the T20 process, which is relatively fluid and changing, the T20 Africa Standing Group emerged as a permanent space of engagement for African scholars. It is a network that brings together more than 30 think tanks from Africa and G20 countries to collaborate specifically on informing the policymaking process of the G20 in relation to its impacts on Africa (Leininger 2017). The group aims to have a consistent presence and mechanisms of communication as well as to follow-up on the recommendations proposed by the group (Begashaw et al. 2018). Among its members in the United Nations Economic Commission for Africa, the T20 Africa Standing Group includes an interlocutor to advance a regional agenda. The existence of this sub-network within a broader global network may be a symptom of the difficulty of creating horizontal partnerships among Northern and Southern peers in the context of persistent asymmetries in power, capacity, and funding. Following Najam's model (2000), the T20 Africa Standing Group is a mechanism to prevent co-optation, which happens when actors have similar strategies but different objectives. In this case, the particular concerns of experts in Africa may have particular positions that are different to those of experts focussed more broadly on the G20 countries. Having a group that thinks of the particular needs of a region prevents these interests from being overshadowed by the broader G20 agenda.

What the previous two sections point to is to an emerging community of think tanks engaged in the global policy space of the 2030 Agenda. By having a national focus and a global reach, the 2030 Agenda allows for a broader range of actors to engage and to share lessons. Although some of the networks analysed emerge from a tradition of international studies and informal diplomacy, a new wave of networks is developing from the broader community of think tanks working on policy issues and agendas. In practice, networks between think tanks will emerge as constellations. Constellations is a valuable metaphor, as they are not fixed entities - they are open and can provide flexible arrangements, whereby a think tank is not just part of one network but can engage in diverse networks, each with specific purposes. What enables collaboration among think tanks, whether North-South or South-South, is a common purpose. Most of the networks described in the previous sections are relatively new and still establishing themselves as well as their purposes, audiences, and 
operating modalities. But what will happen as they become stronger? Or as their agendas begin to diverge? Following Najam's (2000) model, co-optation of these spaces and networks may occur. Whether the stronger parties try to absorb or take over the others has yet to be seen.

\subsection{Southern Think Tank Engagement With OTHER INTERNATIONAL ACTORS}

As discussed in the first section, the global policy space includes a diversity of other actors that think tanks can potentially relate to, such as NGOs, international NGOs, international and multilateral organisations, actors from the private sector, and governments, particularly the offices of the ministries of foreign affairs. Given the relative newness of the SDGs, these relationships are emerging and will most likely include a variety of actors in different partnership compositions.

Relationships between NGOs and think tanks can be complementary if common goals are identified. NGOs and think tanks tend to differ in their strategies for outreach and advocacy. Although NGOs use their values and relationships with broader society as legitimacy tools to engage in policy debates, think tanks base their legitimacy on the findings of their research. In the current context, NGOs can benefit from more support in making sense of the complex 2030 Agenda (Shankland and Constantine 2014) as well as identifying policy options that achieve the goals of NGOs but that are also grounded in research and evidence. At the same time, think tanks may find it valuable to reach out to NGOs to share their policy ideas and recommendations, as NGOs are also relevant actors in development, and their buy-into policy reforms is important. To further these relationships, think tanks and NGOs may need to overcome the mistrust that may emerge from their distinct approaches, even when they have similar goals.

Collaborations with actors from the private sector and governments are challenging, primarily for independent think tanks in the Global South that wish to set clear boundaries on the external influence on their research agendas. In the global space, think tanks can engage with governments beyond their own. In these relationships, funding becomes a key question: Does receiving funds from governments or the private sector undermine a think tank's independence? In the global space, does it undermine the sovereignty of the think tank's own country? There are significant debates on whether think tanks are vehicles for foreign powers to intrude in domestic politics or advocacy fronts for corporations (Baertl Helguero 2018). The global nature of policy debates may accentuate this discussion and the related challenges for think tanks. Transparency becomes an important ingredient for maintaining the independence of think tanks.

Through the Four-C's model, the previous sections explored the relationships of Southern think tanks with each other and with other actors. Think tanks are organisations with a strong capacity to facilitate partnerships and 
dialogues. Collaboration among think tanks from the Global South enables not only a sharing of knowledge among them, but also the opportunity to build bridges between countries. Partnerships involving peers from the Global North are also feasible, but the possibility of co-optation is present in the context of asymmetries of power, capacities, and resources. With other actors, there are also opportunities for cooperation, particularly when the final goals (or ends in the Four-C's model) are aligned. Even then, however, actors would require building trust so that common goals guide these partnerships, even if the strategies (or means) are different.

\subsection{Think Tanks in the Age of Partnerships}

"All countries and all stakeholders, acting in collaborative partnership, will implement this plan", states the declaration of the 2030 Agenda in its second paragraph, setting the tone of global development policy moving forward (United Nations 2016, preamble). Turning these partnerships into practice, however, remains a challenge. This chapter has explored the relationships between think tanks from the Global South with each other, with their Northern peers, and with the broader international community. It shows that collaborations may drive relationships with others, given that some conditions are met.

First, think tanks need to rethink their business models for the age of partnerships. As described in Sect. 32.2 on the implications of the SDGs on think tanks, the 2030 Agenda poses challenges to the work of think tanks-both in how they do research and how they support policy reform. The diversity of actors in the policy debates makes it hard for think tanks to approach only governments-and alone. They need to be working alongside them and collaborating with other organisations that are active in global debates, including NGOs and actors from the private sector. This may require changes to how they carry out research, how they communicate it, and how they engage in policy debates, publicly and behind closed doors. Think tanks also need to be able to develop trust with other actors. Besides, think tanks will need to embrace research strategies and methods that reflect the multi-dimensional challenges of sustainable development.

Second, partnerships need to gain legitimacy, which depends on the extent to which they are inclusive, deliberative, and effective at accomplishing their goals (Verschaeve and Orbie 2016). The participation of more actors from the Global South, including think tanks, may increase the inclusivity of partnerships, which is one key element of legitimacy. The second dimension-being deliberative-requires not only the inclusion of actors, but also their active engagement in the debates and decision-making processes. Applying the FourC's model highlights a challenge of inclusive partnerships when there is an asymmetry of power: the possibility of co-optation. Maintaining a deliberative partnership is more challenging and requires acknowledging and tackling the power asymmetries described in previous sections. 
Finally, partnerships will have to be effective and able to deliver on their mandates. However, partnerships that become more inclusive and deliberative may struggle to make decisions and achieve results. Keeping in mind these aspects can help Southern think tanks and other actors to engage in collaborative partnerships.

\section{Notes}

1. For more information, see https://ottd.onthinktanks.org/directory/.

2. It is quite difficult to account for the total number of think tanks in the world, given their fluid nature. Some organisations that carry out the activities of think tanks in research, policy analysis, and outreach may not consider themselves to be think tanks.

3. Think tanks are research centres that produce research related to policy and conduct outreach and communications activities to share policy ideas and recommendations with policy experts and the broader public.

4. The MDGs had focussed primarily on how to alleviate poverty in developing countries, the role of aid, and more broadly the international community. Now development debates are framed around the SDGs and include economic, social, and environmental dimensions. The discussions are no longer focussed on developing countries but are universal.

5. For more information, please go to http://southernthinktanks.org.

\section{REFERENCES}

Alexander, N., \& Löschmann, H. (2016, December 9). The solar system of G20: Engagement groups. https://www.boell.de/en/2016/12/08/solar-system-g20-eng agement-groups.

Ashoff, G. (2005). Enhancing policy coherence for development: Justification, recognition and approaches to achievement (Studies 11). Bonn: German Development Institute/Deutsches Institut für Entwicklungspolitik (DIE).

Association of Southeast Asian Nations. (2019, February 22). ASEAN think-tanks meet to discuss achieving ASEAN vision and ASCC Blueprint 2025 (ASEAN Secretariat News). https://asean.org/asean-think-tanks-meet-discuss-achieving-asean-vis ion-ascc-blueprint-2025/.

Baertl Helguero, A. (2018). De-constructing credibility factors that affect a think tank's credibility (Working Paper 4). https://medium.com/@info_92670/de-con structing-credibility-722adelf731b.

Begashaw, B., Onubedo, G., Hui, M., \& Chakrabarti, M. (2018). Cooperation with Africa-T20 Africa, G20 and Africa: Assessing our impact and influence. https://t20argentina.org/wp-content/uploads/2018/08/T20-Africa-Monito ring-and-Evaluation-v6.pdf.

Bhattacharya, D., \& Ordóñez-Llanos, A. (2016). Southern perspectives on the post-2015 international development agenda. Abingdon: Routledge.

Council on East Asian Community. (n.d.). NEAT and EAF. http://www.ceac.jp/e/ neat.htm. 
Department of International Relations and Cooperation Republic of South Africa. (2013, November 12). Mid-term meeting of the BRICS Think Tanks Council. http://www.dirco.gov.za/docs/2013/brics1112a.html.

Horner, R., \& Hulme, D. (2019). From international to global development: New geographies of 21 st century development. Development and Change, 50(2), 347378 .

Howes, S. (2014). A framework for understanding aid effectiveness determinants, strategies and tradeoffs: Understanding aid effectiveness. Asia of the Pacific Policy Studies, 1, 58-72.

Jha, A., Kickbusch, I., Taylor, P., \& Abbasi, K. (2016). Accelerating achievement of the Sustainable Development Goals. BMJ, 352(i409), 1-2.

Kimenyi, M. (2013, August 14). Creating global reach: Brookings's partnerships with think tanks in Africa. https://www.brookings.edu/blog/up-front/2013/08/14/ creating-global-reach-brookingss-partnerships-with-think-tanks-in-africa/.

Leininger, J. (2017). "On the table or at the table?" G20 and its cooperation with Africa. Global Summitry, 3(2), 193-205.

Najam, A. (2000). The four C's of government third sector-government relations. Nonprofit Management and Leadership, 10(4), 375-396.

Niblett, R. (2018). Rediscovering a sense of purpose: The challenge for Western thinktanks. International Affairs, 94(6), 1409-1429.

Ordóñez, A., Bellettini, O., Mendizabal, E., Broadbent, E., \& Muller, J. (2012). Influencing as a learning process: Think tanks and the challenge of improving policies and promoting social change. https://idl-bnc-idrc.dspacedirect.org/bitstream/han dle/10625/50230/IDL-50230.pdf.

Parks, T., Maramis, L., Sunchindah, A., \& Wongwatanakul, W. (2018). ASEAN as the architect for regional development cooperation; advancing ASEAN centrality and catalyzing action for sustainable development. http://hdl.handle.net/11540/8970.

Perkins, R. (2013). Sustainable development and the making and unmaking of a developing world. Environment and Planning C: Government and Policy, 31(6), 1003-1022.

Shankland, A., \& Constantine, J. (2014). Defining the post-2015 world: What roles for inclusive rights-based partnerships? In B. Tomlinson (Ed.), Beyond lip service on mutual learning: The potential of CSO and think-tank partnerships for transforming rising powers' contributions to sustainable development (pp. 105-116). East Sussex: Institute of Development Studies.

Stone, D. (2001). Think tanks, global lesson-drawing and networking social policy ideas. Global Social Policy: An Interdisciplinary Journal of Public Policy and Social Development, 1(3), 338-360.

Stone, D. (2007). Recycling bins, garbage cans or think tanks? Three myths regarding policy analysis institutes. Public Administration, 85(2), 259-278.

Stone, D. (2013). Knowledge actors and transnational governance: The private-public policy nexus in the global agora. Basingstoke: Palgrave Macmillan.

United Nations. (2016). Transforming our world: The 2030 Agenda for Sustainable Development. https://sustainabledevelopment.un.org/post2015/transforming ourworld.

Verschaeve, J., \& Orbie, J. (2016). The DAC is dead, long live the DCF? A comparative analysis of the OECD Development Assistance Committee and the UN development cooperation forum. European Journal of Development Research, 28(4), $571-587$. 
Open Access This chapter is licensed under the terms of the Creative Commons Attribution 4.0 International License (http://creativecommons.org/licenses/by/4.0/), which permits use, sharing, adaptation, distribution and reproduction in any medium or format, as long as you give appropriate credit to the original author(s) and the source, provide a link to the Creative Commons license and indicate if changes were made.

The images or other third party material in this chapter are included in the chapter's Creative Commons license, unless indicated otherwise in a credit line to the material. If material is not included in the chapter's Creative Commons license and your intended use is not permitted by statutory regulation or exceeds the permitted use, you will need to obtain permission directly from the copyright holder. 